\section{Attainments in reading and number of teenagers and young adults with Down's syndrome}

\section{Billie Shepperdson}

\author{
Research Fellow, \\ Nuffield Community Care Studies Unit, \\ University of Leicester, U.K.
}

\begin{abstract}
Studies were made of the reading and number abilities of two cohorts of people with Down's syndrome. One cohort consisted of people who were born in the sixties, and the other of people who were born in the seventies. Both cohorts were seen in their teens, and the sixties cohort were also seen in their mid-twenties.
\end{abstract}

The studies confirmed that some people with Down's syndrome are able to master 'academic' skills, and that some people not only retain skills, but continue to improve into the adult years.

Comparing the two cohorts at teenage, more of the seventies cohort possessed 'academic' skills, compared with the sixties cohort at the same chronological age, but the skills of the seventies cohort were not of a substantially higher order.

Looking specifically at reading, in both cohorts teenage language scores were significantly related to reading scores but, for the sixties cohort, there was no relationship between language and reading scores by the midtwenties.

In the sixties cohort more girls than boys could read. In the teens this difference was not significant but it became so in adulthood. This difference between girls and boys was not found in the seventies cohort.

\section{Acknowledgements}

Thanks are due to the people who took part in the studies, their carers and the professionals who helped them. The studies were funded by S.S.R.C. (1972 study), Joseph Rowntree Memorial Trust (1981 studies), E.S.R.C. (Grant No. R000 23 2302) and The Leverhulme Trust (1990 studies).

(C) 1993,1999. The Down Syndrome Educational Trust Down Syndrome Research and Practice

1994, 2 (3) 97-101
Introduction

While the academic achievements of children with Down's syndrome are being given increasing attention, there is little information about how far adults retain, or improve on, their childhood abilities.

There are several case histories of individuals with Down's syndrome which show that some people are able to master reading and number skills (e.g. Hunt, 1966; Duffen, 1976). There is also evidence from studies conducted with larger groups of unselected children and young adults which demonstrate that a proportion of people with the syndrome can learn 'academic' skills. Gibson (1978) is somewhat scathing about progress in these areas, although he concedes that 'a few' people with Down's syndrome do learn to read and write, but it is unclear what proportion constitutes 'a few'.

Buckley (1985) reports some success in teaching reading skills to unselected children with Down's syndrome from two local health districts. While there was considerable variation in the amount of teaching needed and in their subsequent level of competence, 10 of the 11 who remained in the study acquired some reading skills.

Lorenz et al. (1985) used a series of questions to teachers about reading-related skills to tap into the very early prereading and reading abilities of 58 children with Down's syndrome aged 5 to 7 years. Forty four per cent of the 7 year olds were able to read 5 to 10 words. The data suggested that children attending mainstream school had higher reading abilities than those at ESN(M) and ESN(S) schools, even when their mental ages were similar.

Buckley and Sacks (1987) reported that 16 per cent of 90 teenagers with Down's syndrome were 'quite good' readers and could read such things as Enid Blyton's adventure books. About half of the teenagers could add numbers up to 10 , and about a third could subtract. Only 6 per cent could multiply, and 3 per cent divide.

Casey et al. (1988) compared the progress of 18 children with Down's Syndrome in MLD and mainstream schools on a variety of measures. The children were aged between 3 years 8 months and 10 years old. After two years, mainstream children had significantly better scores than MLD children in numeracy, measured on the McCarthy Scales of Children's Abilities. Only 25 per cent of the children were able to score on the Neale Analysis of Reading Ability (word recognition) at the outset of the study and 69 per cent were able to score at the end of two years. More girls than boys could read.

Sloper et al. (1990) examined the academic attainments of 118 children with Down's syndrome aged 7 to 14 years. On the Spar Reading Test only 17 per cent of subjects were able to score and the researchers designed their own checklists on academic abilities so that they could measure very low level abilities. Using multivariable analysis, an association was found between academic achievements and, in order of importance, mental age, type of school, gender, father's locus of control scores, and chronological age. Social class was not found to be related to academic achievements, although social class was related to mental age.

There are few studies which provide information on the 
academic achievements of people at school leaving age and beyond, but an exception is Carr (1988). She found that only 39 per cent of the 41 subjects in her cohort of 21 years olds were able to attain a reading age on the Neale Analysis of Reading Test (mean 7 years 8 months for accuracy and 6 years 9 months for comprehension) although 37 per cent more obtained a 'reading level' based on the ability to recognise some letters. On Vernon's Arithmetic Mathematics Test, 83 per cent could score but, overall, arithmetic ages were more than 2 years below reading ages. Women scored consistently better than men, and those from non-manual families had superior scores compared with those from manual families.

This paper presents further information on the academic attainments of teenagers and young adults with Down's syndrome. The paper also includes information on how far people who can read when they leave school preserve, or build on, their achievements into adulthood.

There has been an increasing emphasis in schools on teaching 'academic' skills to children with Down's syndrome. This paper also examines how far, in practice, these changes have had an impact on people with Down's syndrome by comparing the achievements of two generations of children with the syndrome.

\section{Aims of the study}

1. To describe the achievements in reading and number of teenagers with Down's syndrome and to see how far these abilities are retained, or improved upon, by the mid-twenties, after they have left school.

2. To compare the academic achievements of teenagers born in the sixties with those of teenagers born in the seventies.

3. To examine the relationship between reading scores of teenagers and adults with sex, school attended, and language abilities.

\section{Methods of research}

The research is based upon a series of longitudinal studies of two cohorts of individuals with Down's syndrome brought up at home in South Wales.

The Sixties Cohort was born in 1964 to 1966 and was seen in 1972 (infants), 1981 (teenagers) and 1990-1991 (adults). The study reported here is of those people who remained in the study and were tested at teenage and adult level. There were 49 people.

The Seventies Cohort was born in 1973 to 1975 and was seen in 1981 (infants) and 1990-1991 (teenagers). There were 26 young people. One could not be tested for language abilities.

The methods were the same in all studies: an interview with carers supplemented by the completion of the Gunzburg Progress Assessment Chart, Form 1 at all ages; Form 2 at teenage and adult level only; the Reynell Language Scales at all ages; and the English Picture Vocabulary Test at teenage and adult level only. Only results from the Reynell Language Scales are used in this paper.

Professionals (usually teachers except in the adult study) were asked if the young people recognised any words at all and they were also asked which words the young people recognised on the Schonell Graded Word Reading Test. This test was not completed under standard conditions and so age levels given in the results are included simply as a guide to performance. Scores are most useful for comparing the performance of individuals within the cohort, or between cohorts, with each other.

Professionals were asked to complete a list of 26 items on the young peoples' number abilities. These items ranged from asking about very simple skills (e.g. the ability to count to 5) to more difficult ones (eg the ability to share 10 objects between two people). The items included questions on the ability to recognise shapes and coins.

Differences between the cohorts were tested for significance where appropriate, using the chi-squared test. Correlations between reading and language scores were tested for significance using Pearson's r.

\section{Results}

\section{Reading abilities}

\section{Teenage abilities}

Table 1 shows the reading abilities of both cohorts. The following discussion is restricted to those who could score on the Schonell based test, and they are referred to as 'readers'.

Clearly, some teenagers with Down's syndrome are able to read when they leave school. Comparing the abilities of the two cohorts, although more of the seventies cohort had mastered some of these skills, the difference was not significant. Moreover, the mean level at which they were reading was not substantially greater for the seventies cohort. Indeed, in the two cohorts, the most able readers were in the sixties cohort.

\section{Changes in scores from teenage to adulthood}

Table 1 shows that, in the sixties cohort, some people had lost their reading skills by their mid-twenties. However, while fewer people could read as adults, those who could read were on average more proficient.

Figure 1 shows the individual changes in scores of the sixties cohort over time. Subjects fell into three separate and distinct groups, with very little overlap between them. The progress subjects made between their teens and twenties was closely and consistently related to their teenage score.

Those who were most able at school leaving age tended to make good progress into the adult years. Three girls and one boy (8 per cent) came into this category.

Those with more limited skills at teenage tended to remain at the same level as adults. There were eight girls and one boy (18 per cent) in this category. Two of these did not conform to the usual pattern: the boy became unable to read at all and one girl made more dramatic improvements than the others.

Those who had very poor skills at teenage became unable to read in their twenties. All four (8 per cent) were boys. 
We cannot make any certain predictions about the progress of the seventies cohort in adulthood. However, at teenage, based on criteria from the performance of the sixties cohort, no-one was a very poor reader, i.e. with a reading age of below 6 years 2 months, although one person was borderline. It is, therefore, possible to speculate that if they follow the pattern of the sixties cohort, and this is by no means certain, most people will at least retain their reading skills into adulthood.

In the sixties cohort, no-one who scored under 7 years and 4 months at teenage improved dramatically in their mid-twenties. Seven people in the seventies cohort (27 per cent) fell into this category and so might remain fairly stable.

\begin{tabular}{|l|c|c|c|}
\hline \multirow{2}{*}{ Reading ability } & \multicolumn{2}{|c|}{$\begin{array}{c}\text { Sixties cohort } \\
\mathrm{n}=49\end{array}$} & $\begin{array}{c}\text { Seventies cohort } \\
\mathrm{n}=26\end{array}$ \\
\cline { 2 - 4 } & Teens & Adults & Teens \\
\hline None & $18(37)$ & $22(45)$ & $6(23)$ \\
Own name & $9(18)$ & $11(23)$ & $5(19)$ \\
Some words & $22(45)$ & $16(33)$ & $15(58)$ \\
\hline Total & $49(100)$ & $49(101)$ & $26(100)$ \\
\hline Schonell: & $17(35)$ & $12(25)$ & $15(58)$ \\
Number able to score & 7.3 & 8.6 & 7.6 \\
Mean (yr.mth) & $6.0-9.5$ & $6.7-12.6+$ & $6.4-9.0$ \\
Range (yr.mth) & & & \\
\hline
\end{tabular}

Table 1. Reading ability of both cohorts (\% in brackets).
Eight people (31 per cent) scored above this and so, if they follow the pattern of the sixties cohort, have a possibility of improvement. This includes four (15 per cent) who were at the level (8 years 4 months) where everyone in the sixties cohort improved over time.

\section{Sex and reading ability}

In the sixties cohort at teenage, more girls than boys were able to score on the Schonell based test. By adulthood, girls were significantly more likely to be able to read than the boys ( $p>$.01). In fact, only one boy continued to be able to read in his adult years.

In the seventies cohort at teenage, there were no differences in the abilities of the sexes to read.

\section{Type of school attended and reading ability}

While attendance at the MLD schools for the sixties cohort was a certain mark of superior ability, this was not the case for those in the seventies cohort (Shepperdson, in press). Even so, there is some relationship between abilities and the school attended (although not a perfect one), and so it is not surprising to find that, taking both cohorts together, only 32 per cent of children in SLD schools could read compared with 86 per cent of those in MLD schools.

Looking simply at readers, 65 per cent of all readers in the sixties cohort were in the SLD school compared with 27 percent in the seventies cohort. This demonstrates that some pupils certainly are taught to read in the SLD schools.

\section{Language ability and reading scores}

It would be tempting to examine abilities in language to suggest whether or not there were children who, in spite of having the potential to read, were not mastering this skill. Unfortunately, the relationship between language and reading skills is unlikely to be straightforward. Certainly those who scored highly on the Reynell Language Scales (and, indeed, on other measures) were more likely to be able to read, and vice versa. This does not necessarily imply any causal link. These young people were also, on the whole, more capable altogether. Consequently, it may be that those with more advanced language skills tend to do well on most tests and tend to be able to perform other more complex tasks, of which reading is one. In other words, it may be that

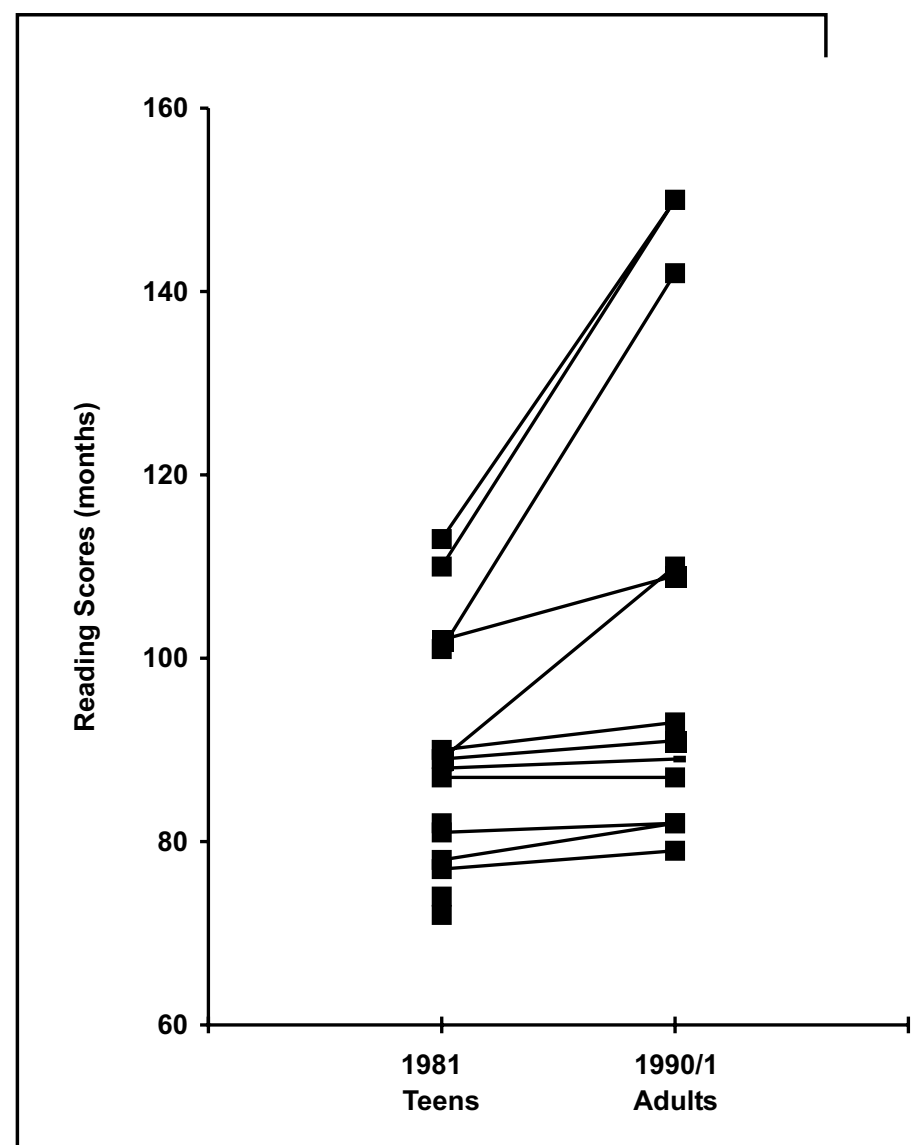

Figure 1. Changes in reading scores: teens to adult (based on Schonell Graded Word Reading Test).

there is no unique relationship between the two abilities. In any case, and to complicate any relationship between language and reading skills yet further, Buckley and Bird (1993) suggest that learning to read may itself encourage the acquisition of language.

So, leaving aside any suggestions of causality and looking simply at readers, reading scores at teenage for both cohorts were significantly correlated with language scores. This was 
not the case for the adults in the sixties cohort. So, in the adult years, the relationship with reading level and the Reynell scores was imperfect (see Table 2). To give practical examples of this, there were people who, by their Reynell adult scores, should have been good adult readers but had only moderate skills and one, in contrast, had a moderate adult Reynell score of only 56 and yet was a very good reader in the adult years.

\begin{tabular}{|l|l|l|}
\hline Sixties cohort & $\begin{array}{l}\text { Teens } \\
\text { Adults }\end{array}$ & $\begin{array}{l}r=.67 ; \mathrm{d} . \mathrm{f}=15 ; \mathrm{p}<.01 \\
\mathrm{r}=.44 ; \mathrm{d} . \mathrm{f} .=10 ; \text { not significant }\end{array}$ \\
\hline Seventies cohort & Teens & $\mathrm{r}=.51 ; \mathrm{d} . \mathrm{f} .=12 ; \mathrm{p}<.05$ \\
\hline
\end{tabular}

Table 2. Correlations between reading and language scores for both the cohorts.

Figure 2 shows the range and mean teenage scores of readers and non-readers on the Reynell Language Scales. It illustrates that there is a considerable overlap between Reynell scores and the ability to read. However, in the sixties cohort, those who had poor Reynell scores at teenage did not go on as adults to be readers. The cut off point on the Reynell Scales for people who read as adults was 49 and no one who scored less than this in their teens retained their ability to read into adulthood. There were 5 subjects in the sixties cohort who scored over 50 , but yet could not read (one in mainstream, one in a unit attached to mainstream, and 3 in SLD schools).

There were two teenagers in the seventies cohort with scores on the Reynell of over 50 but who could not read (one in SLD school and one in MLD school).

\section{Numerical abilities}

Figure 3 shows the differences in mean scores of subjects on the 26 number items.

The results suggest that the sixties cohort subjects made little improvement over the teen to adult period, but this is deceptive because 15 subjects gained skills (mean 7.2 gains) and 23 others lost them (mean 4.3 losses). There was no clear reason to explain who lost and who gained.

To look more closely at scores at the top and bottom of the range, there were 9 teenagers in the sixties cohort who were unable to score at all and this had increased to 15 subjects who lacked any numerical skills by adulthood. However, those who lost all skills were those who had modest abilities anyway in their teens. Turning to the high achievers, two people scored over 25 at teenage and seven scored over 25 as adults. While some of the high teenage scorers (i.e. over 20 points) certainly did lose scores in adulthood, it is encouraging to note that no high scorer lost all their skills. The largest drop in this category of subjects was from 25 to 17 points. As with reading, able people were more inclined to retain, or improve, skills into adulthood than others with more limited abilities.

The seventies cohort subjects scored rather better than the sixties cohort subjects had done in their teens (a mean of 14.2 compared with 10.3). Three (12 per cent) scored over 25 (4 per cent in the sixties cohort). Four (15 per cent) were unable to score at all in the seventies cohort compared with 18 per cent in the sixties cohort.

\section{School attended and numerical abilities}

Table 3 shows the numerical abilities of subjects and the final type of school at which they were educated.

The range of scores at SLD and MLD schools suggests that, for both cohorts, those children who attended SLD schools were given the opportunity to master basic numerical skills.

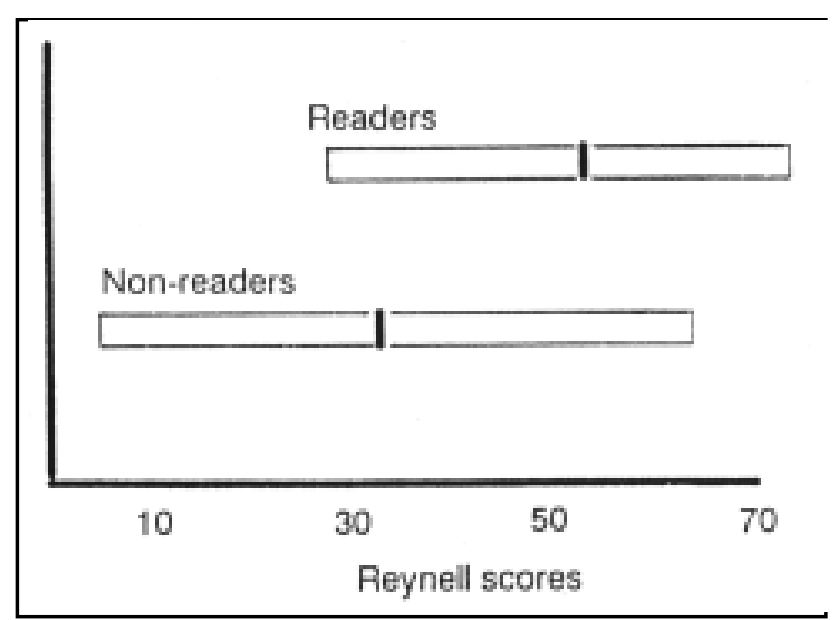

Figure 2. Teenage Reynell scores and reading ability (both cohorts).

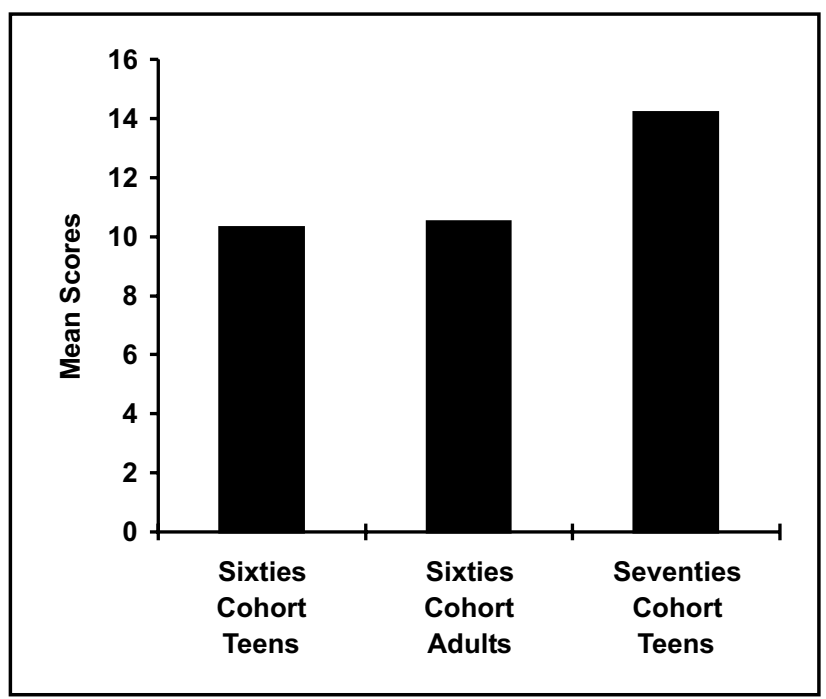

Figure 3. Mean scores on number (both cohorts).

In both cohorts there was an overlap between pupils at SLD and MLD schools, with some of the SLD pupils scoring more highly than some of the MLD pupils. However, the range of scores shows that the overlap in scores was greater for the seventies cohort. In contrast, all MLD pupils in the sixties cohort scored highly and this probably reflects the more restricted access to MLD schools that there was for the sixties cohort (Shepperdson, in press).

\section{Conclusions}

\section{Reading}

In keeping with the findings from other studies, it is clear that some people with Down's syndrome can and do learn to read as children. In the seventies cohort more teenagers with Down's syndrome were able to read, but not significantly more of them, and nor did the readers score substantially better than the sixties cohort readers at the same stage. 


\begin{tabular}{|l|c|c|c|c|}
\hline \hline School & $\mathrm{n}$ & $\begin{array}{c}\text { Sixties cohort } \\
\text { Teenagers 1981 } \\
\text { mean (range) }\end{array}$ & $\mathrm{n}$ & $\begin{array}{c}\text { Seventies cohort } \\
\text { Teenagers 1990 } \\
\text { mean (range) }\end{array}$ \\
\hline SLD & 31 & $8.0(0-25)$ & $10^{*}$ & $8.8(0-23)$ \\
MLD & 5 & $23.6(21-26)$ & 10 & $18.3(5-26)$ \\
Mainstream & 1 & 17.0 & 2 & $15.5(10-21)$ \\
Unit & 1 & 17.0 & 1 & 22.0 \\
Residential & 10 & $9.1(0-20)$ & 3 & $15.3(12-18)$ \\
None & 1 & 0 & - & - \\
\hline Total & 49 & $10.3(0-26)$ & 26 & $14.2(0-26)$ \\
\hline
\end{tabular}

word building (rather than relying on look and say), there are many opportunities to use the skill and so build on basic abilities.

These results show the academic achievements of two cohorts of people with Down's syndrome but it is important to stress that we do not know what proportion of people with Down's syndrome would learn academic skills, or what level they would achieve if they were all exposed to regular teaching. Nor do we know how far abilities would remain more stable, or how far people would continue to make gains, if they continued to be taught from their teens into adulthood.

Table 3. School attended and numerical abilities (mean numerical items known).

In the sixties cohort, teenage and adult reading abilities were closely related with the able readers all continuing to make substantial gains into their twenties, and all the least able not retaining any skills.

In the sixties cohort, girls were significantly better readers than boys at the adult level but this difference was not found in the seventies cohort.

\section{Number}

The results show that some subjects with Down's syndrome are able to master simple skills in number. Not only were there more people in the seventies cohort with numerical skills, mean scores were also higher than for the sixties cohort at the same stage. The fact that the seventies cohort scored more highly than the sixties cohort implies that, if they are taught, individuals can learn.

Some of those who had reasonable number scores at teenage slipped a little in the adult years, but they did not lose all their abilities. While there were examples of some people who had very poor skills who did not improve and, in fact, lost skills, comparing those who gained with those who lost, overall more points were gained than were lost in the teen to adult period.

The results show that pupils at both MLD and SLD schools were taught numerical skills and, indeed, some of the pupils in SLD schools surpassed others in the MLD schools.

\section{Reading and number}

Comparing abilities in number and reading, in number the seventies cohort did better than the sixties cohort both as teenagers and adults. In reading this was not the case. The mean scores for teenagers in the seventies cohort were lower than mean scores for adults in the sixties cohort.

Numerical abilities seemed to be less tenacious than those in reading and even some who were good at number lost skills between their teen and adult years. In contrast, no really good reader lost skills between teens and adulthood, but, on the contrary, such readers (while few in number) went from strength to strength. It is possible to speculate that, once a person has mastered the principles of letter sounds and

\section{References}

Buckley,S. (1985) Attaining basic educational skills: reading, writing and number. In Lane,D. and Stratford,B. Current Approaches to Down's Syndrome. Holt, Rinehart and Winston. Buckley,S. and Bird,G. (1993) Teaching children with Down's syndrome to read. Down's syndrome: Research and Practice, 1(1), 34-39.

Buckley,S. and Sacks,B. (1987)Theadolescent with Down's syndrome. Portsmouth Polytechnic.

Carr,J. (1988) Six weeks to twenty-one years old: a longitudinal study of children with Down's syndrome and their families. Journal of Child Psychology and Psychiatry Vol. 29 No.4 407-431.

Casey,W., Jones,D., Kugler,B. and Watkins,B. (1988) Integration of Down's syndrome children in the primary school: a longitudinal study of cognitive development and academic attainments. British Journal of Educational Psychology 55, 297-286.

Duffen,L. (1976)Teaching reading to children with little or no language. Remedial Education. 11. 139.

Gibson,D. (1978) Down's syndrome: the psychology of mongolism. London: CUP

Hunt,L. (1967) The World of Nigel Hunt. London: Darwen Finlayson.

Lorenz,S., Sloper,P., Cunningham,C. (1985) Reading and Down's syndrome. British Journal of Special Education, Vol.13 No.2. 65-67.

Sloper,P., Cunningham,C., Turner,S., Knussen,C. (1990) Factors related to the academic attainments of children with Down's syndrome. British Journal of Educational Psychology 60. 284-298.

Shepperdson,B. (In press) Changes in the educational placements of children with Down's syndrome. Research in Education.

Address for correspondence:

Dr Billie Shepperdson,

University of Leicester,

Nuffield Community Care Studies Unit,

Department of Epidemiology and Public Health, 108 Regent Road,

Leicester, LE1 7LT, U.K. 